\title{
The convergence on extremes
}

\author{
Gaetano Rocco, MD, FRCSEd
}

\footnotetext{
From the Division of Thoracic Surgery, Thoracic Department, Istituto Nazionale Tumori, IRCCS, Fondazione Pascale, Naples, Italy.

Disclosures: Author has nothing to disclose with regard to commercial support.

Received for publication Feb 22, 2018; accepted for publication Feb 22, 2018; available ahead of print April 4, 2018.

Address for reprints: Gaetano Rocco, MD, FRCSEd, Division of Thoracic Surgery, Thoracic Department, Istituto

Nazionale Tumori, IRCCS, Fondazione Pascale, Naples, Italy (E-mail: g.rocco@ istitutotumori.na.it).

J Thorac Cardiovasc Surg 2018;156:376-7

$0022-5223 / \$ 36.00$

Copyright $(2018$ by The American Association for Thoracic Surgery

https://doi.org/10.1016/j.jtcvs.2018.02.062
}

In statistics, the study of the extremes of a Gaussian curve may be of interest to understand the characteristics of a population not from the most common values but from the maximal or minimal values recurring in time. ${ }^{1}$ The socalled Gumbel distribution is used in epidemiology and, in particular, in geography to cluster phenomena (ie, floods) where maximal precipitations are examined to predict the occurrence of such phenomena. ${ }^{2}$ This method also is used in oncology to understand specific cancer epidemiology within a certain region in an attempt at connecting disease episodes that may otherwise appear unrelated and occasional. ${ }^{1,2}$ The Gumbel distribution is a clear example of how the investigators may draw sensible information by converging on extremes.

In the last 20 years, with the advent of thoracoscopic surgery and the refinements of the lung cancer TNM staging system, wedge resection and pneumonectomy have become the extremes of a thoracic surgical practice. The latter is infrequently performed for those extents of disease when saving of the parenchyma is not technically feasible or recommendable but completeness of resection is desired. Currently, surgeons report their primary pneumonectomy figures almost with reluctance, feeling somewhat entitled to use this procedure only after complex neoadjuvant treatments. In fact, recent series on pneumonectomy after induction treatment demonstrate acceptable mortality and morbidity rates that cannot go unnoticed. ${ }^{3}$ On the other end of the spectrum, wedge resections have long represented a compromise solution for primary lung cancers, fraught with recurrence rates that have attracted the interest of stereotactic body radiation therapy (SBRT) advocates. ${ }^{4,5}$ Along the line of recent evidence emerging from the literature, ${ }^{6}$ the article by Ajmani and colleagues ${ }^{7}$ analyzes the National Cancer Data Base in an attempt at revisiting the oncological value of wedge resection by focusing on the quality of the procedure. ${ }^{7}$ Indeed, tumor-free margins associated with the removal of at least 5 lymph nodes were favorable prognosticators compared by propensity matching to patients treated with SBRT after adjustment

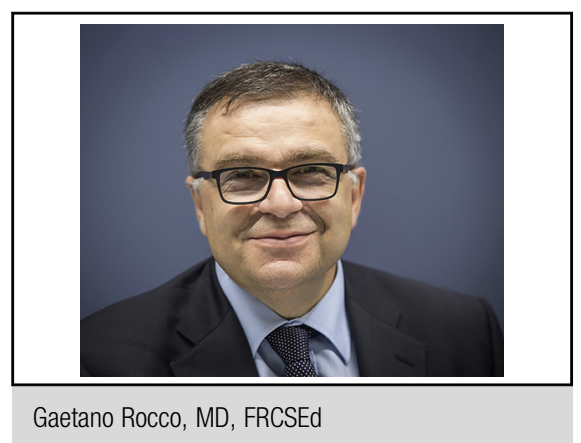

Central Message

A well-performed wedge resection is still a valuable option in selected patients with lung cancer.

See Article page 380 for demographic and clinical variables. ${ }^{7}$ Far from delineating a sort of surgical counter-offense against the trendy new treatment modality (ie, SBRT), this contribution raises several issues to be addressed to better define our current practice. First, in a fashion similar to SBRT, we can actively modulate our surgical choice to fit the needs of the individual patient. However, thoracic surgeons must know that by performing a wedge resection for primary lung cancerwithout the certainty of clear margins and adequate nodal sampling - the quality of the procedure will be impaired. ${ }^{6,7}$ In addition, for early-stage lung cancers, the survival outcomes obtained after carefully scheduled and performed wedge resections (associated with lymphadenectomy) may not differ from the ones observed with segmentectomies. ${ }^{6}$ In fact, the presence of a solid component and the tumor spread through air spaces phenomenon may play a significant role in determining the recurrence rate after wedge resection for lesions measuring less than $2 \mathrm{~cm}$ in diameter. ${ }^{9-11}$ Whether the lack of compliance with tumorfree margins and extent of lymphadenectomy as new quality metrics may translate into a survival disadvantage of wedge resection compared with SBRT needs to be assessed by the much-awaited randomized trials. ${ }^{12}$ Second, patients and colleagues must know that, like pneumonectomies, wellplanned wedge resections may still serve a viable oncological purpose. In addition, these procedures can be done by video-assisted thoracoscopic surgery, more often than in the past via a single small incision, in awake or nonintubated selected patients and without placing a chest tube at the end. ${ }^{13}$ In this setting, the addition of an adequate nodal dissection should not affect the procedure-related morbidity 
and hospital stay. ${ }^{8}$ Accordingly, in selected patients, a wellperformed wedge resection may represent an excellent operative step of an advanced Enhanced Recovery After Surgery protocol aimed at configuring a 1-day lung cancer surgery pathway according to a fast-track model that may become the surgical benchmark against which any other local treatment modality must be compared. ${ }^{14}$

More than a mathematical and philosophical model, the convergence on extremes of our thoracic surgical armamentarium may represent the key for a treatment planning characterized by a more granular distinction of the type of procedure according to the patients' characteristics, stage of disease, and nodule size and density, as well as the level of expertise in minimally invasive surgery.

\section{References}

1. Jung I, Park G. P-value approximations for spatial scan statistics using extreme value distributions. Stat Med. 2015;34:504-14.

2. Abrams AM, Kleinman K, Kulldorff M. Gumbel based p-value approximations for spatial scan statistics. Int J Health Geogr. 2010;9:61.

3. Pless M, Stupp R, Ris HB, Stahel RA, Weder W, Thierstein S, et al; SAKK Lung Cancer Project Group. Induction chemoradiation in stage IIIA/N2 non-small-cell lung cancer: a phase 3 randomised trial. Lancet. 2015;386:1049-56.

4. Landreneau RJ, Sugarbaker DJ, Mack MJ, Hazelrigg SR, Luketich JD, Fetterman L, et al. Wedge resection versus lobectomy for stage I (T1 N0 M0) non-small-cell lung cancer. J Thorac Cardiovasc Surg. 1997;113:691-8.

5. Zheng X, Schipper M, Kidwell K, Lin J, Reddy R, Ren Y, et al. Survival outcome after stereotactic body radiation therapy and surgery for stage I non-small cell lung cancer: a meta-analysis. Int J Radiat Oncol Biol Phys. 2014;90:603-11.
6. Altorki NK, Kamel MK, Narula N, Ghaly G, Nasar A, Rahouma M, et al. Anatomical segmentectomy and wedge resections are associated with comparable outcomes for patients with small cT1N0 non-small cell lung cancer. J Thorac Oncol. 2016;11:1984-92.

7. Ajmani GS, Wang CS, Kim KW, Howington JA, Krantz SB. Surgical quality of wedge resection impacts overall survival in patients with early stage non-small cell lung cancer. J Thorac Cardiovasc Surg. 2018;156:380-91.

8. Stiles BM, Kamel MK, Nasar A, Harrison S, Nguyen AB, Lee P, et al. The importance of lymph node dissection accompanying wedge resection for clinical stage IA lung cancer. Eur J Cardiothorac Surg. 2017;51:511-7.

9. Mohiuddin K, Haneuse S, Sofer T, Gill R, Jaklitsch MT, Colson YL, et al. Relationship between margin distance and local recurrence among patients undergoing wedge resection for small $(<2 \mathrm{~cm})$ non-small cell lung cancer. $J$ Thorac Cardiovasc Surg. 2014;147:1169-75.

10. Moon Y, Sung SW, Moon SW, Park JK. Risk factors for recurrence after sublobar resection in patients with small $(2 \mathrm{~cm}$ or less) non-small cell lung cancer presenting as a solid-predominant tumor on chest computed tomography. J Thorac Dis. 2016;8:2018-26.

11. Kadota K, Nitadori J, Sima CS, Ujiie H, Rizk NP, Jones DR, et al. Tumor spread through air spaces is an important pattern of invasion and impacts the frequency and location of recurrences after limited resection for small stage I lung adenocarcinomas. J Thorac Oncol. 2015;10:806-14.

12. Moghanaki D, Simone CB II, Rimner A, Karas TZ, Donington J, Shirvani SM et al; ASTRO Evidence-Based Guideline Committee for Stereotactic Body Radiation Therapy (SBRT) for Early-Stage Non-Small Cell Lung Cancer. The value of collaboration between thoracic surgeons and radiation oncologists while awaiting evidence in operable stage I non-small cell lung cancer. J Thorac Cardiovasc Surg. 2018;155:429-31.

13. Yang SM, Wang ML, Hung MH, Hsu HH, Cheng YJ, Chen JS. Tubeless uniportal thoracoscopic wedge resection for peripheral lung nodules. Ann Thorac Surg. 2017;103:462-8.

14. Rogers LJ, Bleetman D, Messenger DE, Joshi NA, Wood L, Rasburn NJ, et al. The impact of enhanced recovery after surgery (ERAS) protocol compliance on morbidity from resection for primary lung cancer. J Thorac Cardiovasc Surg. December 19, 2017 [Epub ahead of print]. 